\title{
USING AHP AND ANP TO EVALUATE THE RELATION BETWEEN REVERSE LOGISTICS AND CORPORATE PERFORMANCE IN BRAZILIAN AUTOMOTIVE INDUSTRY
}

\author{
Cecilia Toledo Hernández \\ São Paulo State University (UNESP) \\ Guaratinguetá, SP, Brazil \\ E-mail: ctoledo2002@yahoo.es \\ Fernando Augusto Silva Marins \\ São Paulo State University (UNESP) \\ Guaratinguetá, SP, Brazil \\ E-mail: fmarins@,feg.unesp.br \\ Phelipe Medeiros da Rocha \\ PSA Peugeot Citroën Automobiles \\ Porto Real, RJ, Brazil \\ E-mail: phelipe.rocha@mpsa.com
}

\begin{abstract}
Reverse Logistics (RL) activities are practiced by most Brazilian industries, including the automotive one. However, a relevant problem is to identify how different RL programs can affect corporate performance indicators. Analytic Hierarchy Process (AHP) is one of the analytical tools, which can be used to handle a multi-criteria decision-making problem and the Analytic Network Process (ANP) is a similar technique, but can capture the interdependencies between the criteria under consideration. Both approaches were adopted here to study the influence of RL practices in automotive corporate performance. Preliminary results indicated that both methods can be used, being AHP the most efficient, because it requires a smaller number of judgment, and ANP the most reliable, because it considers element dependencies, which is more compatible to the reality of the Brazilian automotive sector.
\end{abstract}

Keywords: Analytic Hierarchy Process (AHP), Analytic Network Process (ANP), Reverse Logistics, Brazilian Automotive Industry

\section{Introduction}

The sustainability theme has acquired great importance in business and academic fields, as well as in society in general. This concept is basically being introduced in companies by environmental regulations. Clean production, reduction, re-use, recycling and other strategies are used in order to satisfy actual needs without compromising the future.

Reverse Logistics (RL) is defined as the business logistics area responsible for planning, operating and controlling of raw materials reverse flows, in-process inventory, finished products, and their information, from the consumption point to the origin point in order to recapture value or adjust destination (Rogers \& Tibben-Lembke, 1998). It can generate several benefits, including productivity gains, which react on economic, social and environmental spheres. 
Better customer service, reduction of operation costs, increase of brand prestige and corporate image have been identified as potential benefits of RL programs (Daugherty, Autry and Ellinger, 2001) that can be an alternative source of income, contributing to business sustainability (Braga Junior, Costa and Merlo, 2006). RL in the recycling channel allows to reach economic and corporate image aims, reducing wastes and residues (Souza, Vasconcelos and Pereira, 2006; Cruz \& Ballista, 2006). RL practices affect positively and strongly performance indicators, which are closely linked to corporate sustainability concept, but it is still hard to evaluate this impact quantitatively (Hernández, Marins and Castro, 2007).

Brazilian automotive industry does not escape from this reality. Corporate strategies have been showing advances in sustainability and corporate social responsibility issues (Neto, 2008). RL, both in its broader meaning, defined as all operations related to products and material re-use (Revlog, 2004), and its logistical procedure meaning, regarding the material flow returning to company for any reason, has been earning its role in that context, therefore it is necessary to identify and evaluate RL contribution to corporate performance.

This work analyzes sustainable practices identified in automotive companies operating in Brazil, which can be gotten into groups of different RL programs - economic, image and corporate citizenship drivers - in order to evaluate the influence in corporate performance by using Analytic Hierarchy Process (AHP) and Analytic Network Process (ANP) to reach a conclusion of which method provides a better result.

Interviews with specialists were conducted in order to collect and validate data in the research preliminary phase. This qualitative and exploratory approach was fundamental to familiarize with the problem, and afterwards a quantitative approach allowed obtaining decision criteria and subcriteria as well as gave them weight or importance, establishing dependency relations in the model here proposed.

This paper is organized in 5 sections. It begins by the introduction, in section 2 it is made the relation between RL and corporate performance by Balanced Scorecard (BSC) perspectives, exemplifying the automobile industry strategies. The section 3 describes the research methodology, being defined and developed the model used in this type of industry, and the section 4 presents the results of the methods applications. Finally, there are conclusions, restrictions, future researches and references.

\section{Corporate performance and RL}

The company sustainability and perpetuity in the long term have become aims with the same level of profit necessity in the short term so, besides the pursuit of gain, it is necessary to honor a great variety of social, environmental and government interests to ensure profitability for a long time.

RL is inserted in this context of multiple satisfactions, since a lot of productivity gains are obtained by RL practices. There are also several strategic drivers that support its implementation: economic factors, legislations, corporate citizenship, environmental aspects (Rogers \& Tibben-Lembke, 1998); economic aspects, marketing and legal (Fleischman, 2000); economic aspects, corporate citizenship, image, customer service and legal (Leite, 2006).

Although the benefits of RL programs are known, the reality of the Brazilian companies doesn't show explicitly all advantages linked to performance, because according to BSC (Kaplan \& Norton, 1997) they are a combination of financial and non-financial indicators.

BSC was designed initially as a solution to measure performance, but subsequently it was proved as a strategic management tool to formulate or implement strategies (Kaplan \& Norton, 1997). 
This work employs 4 BSC perspectives to show how RL programs can affect corporate performance indicators in the Brazilian automotive industry. Table 1 summarizes the perspectives and the indicators that can be affected by RL practices.

Table 1. Corporate performance indicators related to RL (Hernández, Marins and Castro, 2007).

\begin{tabular}{|l|l|}
\hline Perspectives & Corporate performance indicators \\
\hline Financial & $\begin{array}{l}\text { Traditional economic-financial indicators } \\
\text { Shareholder value } \\
\text { Access to capital }\end{array}$ \\
\hline Customer & $\begin{array}{l}\text { Customer attraction and retention } \\
\text { Brand value and reputation }\end{array}$ \\
\hline Internal processes & $\begin{array}{l}\text { Operational efficiency } \\
\text { Innovation }\end{array}$ \\
\hline Learning and Growth & $\begin{array}{l}\text { Professional growth } \\
\text { Productivity of human resources }\end{array}$ \\
\hline
\end{tabular}

\subsection{Financial perspective}

Although logistics activities are consumers of financial resources, value recapture of returned materials can be an attractive activity for many companies (Rogers \& Tibben-Lembke, 1998). Recycling provides earnings that stimulate new initiatives to development and improvement of RL practices. According to Leite (2006), economic recovery is the basic reason to corporate use of these practices in Brazil.

Besides providing profit, an enterprise has to generate value for its owners and shareholders. Nowadays, this value also becomes an investment indicator. Financial institutions use social and environmental checklists to measure credit risk. In Brazil, it is greatly used the Managerial Sustainability Index (ISE) to evaluate investments (Silva \& Quelhas, 2006).

RL programs basically with economic, image and corporate citizenship drivers are linked directly or indirectly to economic results. Therefore, they influence most corporate performance indicators (Hernández, Marins and Castro, 2007).

The development of RL programs has the economical issue as main propulsive. Residues recycling and packing re-use lead to substantial savings (Neto, 2008), but the environmental protection is an evidenced point in these programs for getting image and corporate citizenship results.

\subsection{Customer perspective}

According to Valente (2002) apud Chaves \& Alcântara (2006) "customer satisfaction is not simply reduced to acquisition of products and services, but a continuous evaluation before and after sale". Thus, RL can generate competitive advantage through increasing in the service level offered to customers by marketing relationship after-sale.

Studies conducted by Rogers \& Tibben-Lembke (1998) in American companies in the second half of the 90's showed that the principal strategic reason for those companies operate reverse channels were the increase of the productivity, which enabled service differentiation.

Similar studies carried out in Brazil in 2004 and 2005 demonstrated that economic targets had been gaining bigger importance in RL programs, but customer retention, by adoption of liberal policies to the return of non-consumed products and offered services, keeps on an important strategic objective to achieve competitiveness in many companies (Leite, 2006). Consumers' requirements are a fundamental reason for several companies operate reverse channels (Sinnecker, 2007), thus it is possible to say that RL has strong impact on customer attraction and retention (Hernández, Marins and Castro, 2007). 
RL allows companies to express actions that are not directly linked to their products, but strengthen their significance by making positive associations. Leite (2005) states that creation of corporate image, at the consumer's perception, has subjective character. This perception is formed from relationship developed between company and consumer during all negotiation stages, including relationship with society and environment. An adequate management of reverse channels can improve corporate image from the treatment of remnants, contributing to the social welfare with donations and environmental conservation with material recycling (Tibben-Lembke, 2000), influencing positively and strongly in company reputation and corporate social responsibility.

In Brazil, most industries have been stood out by relations fixed to communities where they are located. They promote social actions and environment protection programs in which are involved common citizens (Epelbaum, 2004; Neto, 2008).

\subsection{Internal processes perspective}

Kaplan \& Norton (2000) comment that all internal processes are important and must be well carried out, but some of them cause bigger impact on value proposition to customers. Managers must do clear identification of these processes, in each particular case, to a successful BSC implementation (Campos, 2001).

Achieving operational excellence is a target of each company, productivity indicators and costs are identified with a satisfactory processes performance. RL practices give economic gains when manufacturing use components and materials recovered by recycling (Leite, 2005).

Rovere (2005) apud Amaral (2003) mentions the inclusion of the technological dimension on the concept of sustainability, evaluating efforts companies make to create new technologies that are able to develop cleaner and more economical processes. The technological innovations, which bring better use of resources available for recycling, are extremely important to structure reverse channels. According to Leite's rating (2000), technology is necessary to ensure essential conditions in establishing post-consumption reserve flows and legislation can be a modification factor because can develop new technologies. Brazilian business reality indicates there are few programs with legal drivers and the automotive sector does not escape from this situation, therefore legislation compliance does not appear as an important factor in corporate scenario (Leite, 2006). But establishing of minimum levels for recovering is part of European companies' everyday, under the legal punishment of lose operation license, and this may be a decisive factor for creativity and innovation increase (Hammond \& Beulles, 2007).

The concept of product life cycle for logistics comes from conception to final destination, no matter which: discarding, repair or reusing (Triguero, 2002). Automotive companies invest strongly in material reduction, including the application of biodegradable products. Since the conception, there is preoccupation with destination after lifetime and this is a fundamental part of RL concept.

\subsection{Learning and growth perspective}

Learning and functional growth of an enterprise mean its capacity to maintain human resources in high level of motivation, satisfaction and productivity. Norton \& Kaplan (2000) cites, in a study with different companies, value accounting of tangible assets is not greater than $15 \%$ of market value, the last is imputed to intangible assets related to knowledge, intellectual and human capital. According to Herrero (2005), human capital can be understood as intellectual (knowledge, information, industrial property, experience) that can be used to generate wealth.

Therefore human capital is an important factor for companies' survival and renewal in all activity levels. RL policies require skilled and trained human resources and strategic investment (Hernández, Marins and Castro, 2007). 
Figure 1 summarizes hierarchically various indicators here analyzed. They are grouped in BSC perspectives and it is shown how different RL programs can influence them.

It is important to mention that the effect of RL programs on performance indicators can vary according to several factors, such as the type of business sector, value chain, and position of the reverse channel. Then in-depth studies must be developed for each case, like this one specifically to Brazilian automotive industry.

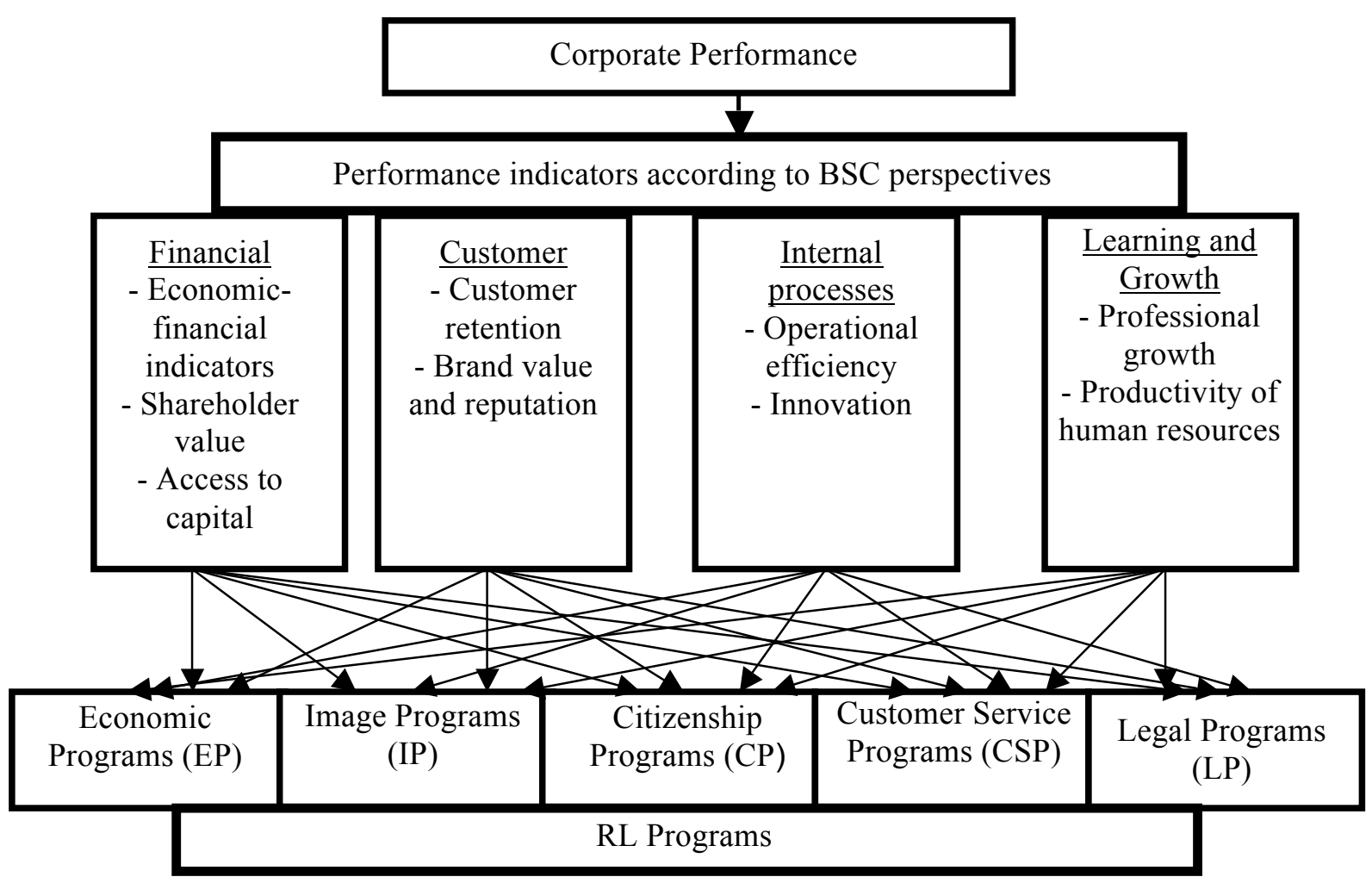

Figure 1. Corporate performance and RL (Hernández, Marins and Castro, 2007).

\section{Research methodology}

According to Lakatos \& Marconi (1986), a research problem relates to analysis of a theme or a knowledge gap still without solution, which can be set out by a question that specifies the subject. In this study the main question is: can the methods AHP and ANP be used to evaluate the relation between RL and corporate performance indicators? Since theoretical knowledge is limited, it needs to touch on exploratory.

At first, in order to render the research, it was used a qualitative approach. In this type of research, researcher is the key instrument and tends to an inductive data analysis.

Secondary data collection provides from academic literature review, fundamentally from studies published about RL and corporate performance (Hernández, Marins and Castro, 2007, 2008), sustainability in Brazilian automotive industry, where are described sustainable practices of 13 industries that operate in Brazil (Neto, 2008) and using of ANP to define RL strategic performances (Ravi, Shankar and Tiwari, 2005; Wu \& Lee, 2007; Cheng \& Li, 2007).

Primary data were obtained from unstructured interviews with several managers and specialists of an automotive industry, not included in the preliminary study, which was useful to complement and cross information. This way of collection served as base to identify elements to be in-depth (Vergara, 2005) 
and to reach specific activities developed by automotive industry to reduce its environmental impacts, considering that it tackles just activities related to automotive production process, not those one which are related to product use.

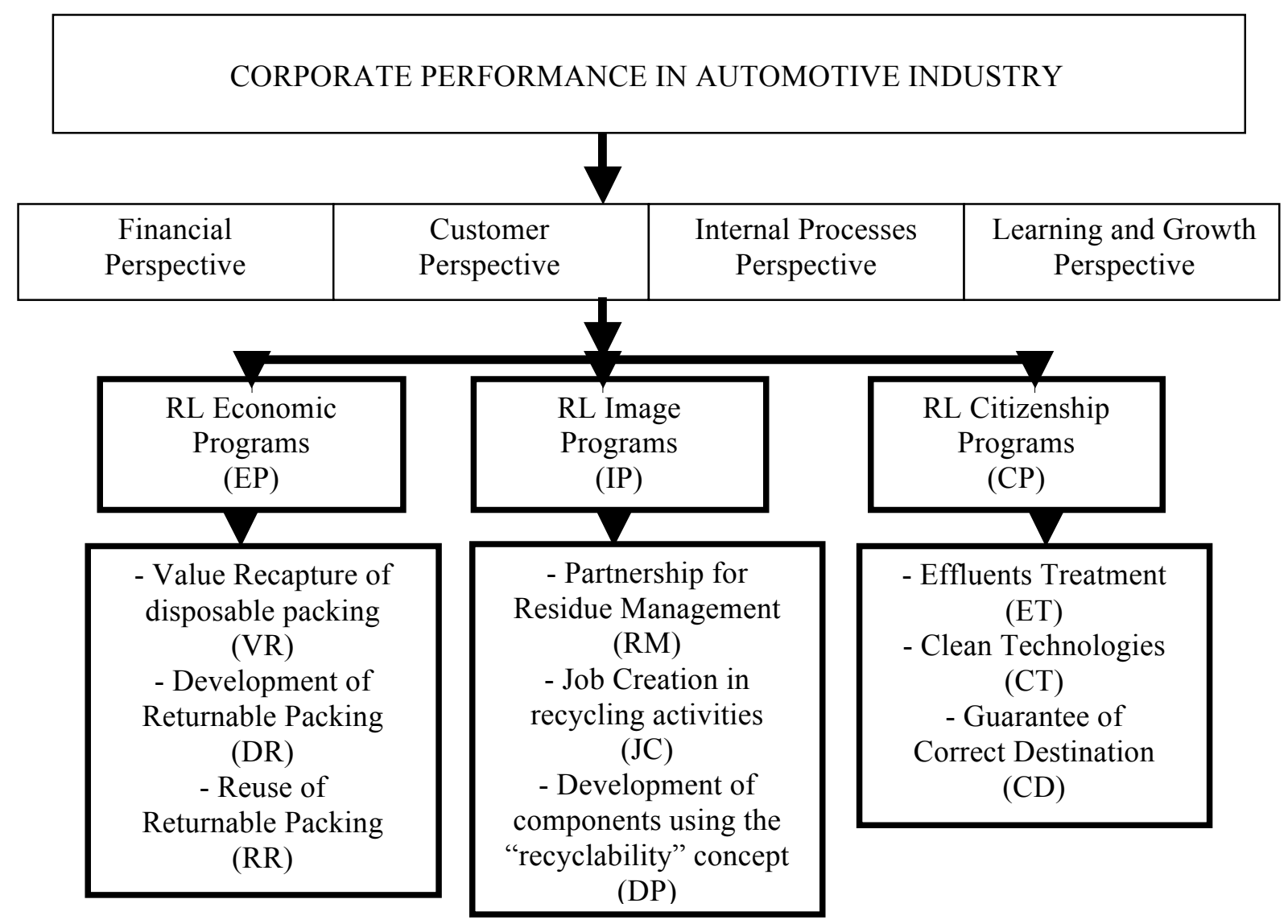

Figure 2. Hierarchical model for RL operations in automotive industry.

In second phase of research where, from the model shown in Figure 2 and by quantitative approach, values of importance were attributed to criteria and subcriteria. Interviews were used as data collection tool in order to obtain these values. Due to the way needed to get information for AHP/ANP applications (which involve comparison of hierarchy levels for RL activities and indicators), it was left behind the use of questionnaires. The researched population, basically specialists and managers from logistics area, wasn't familiar to the methods. Therefore, a face-to-face contact was indispensable to clarify points of view.

\section{Result analysis}

AHP and ANP (Saaty, 2008), considering the last as an extension of the first, are Multiple Criteria Decision Making (MCDM) methods that use a decision matrix as basic tool.

Taliscali \& Ercan (2006) apud Alves, Simões and Neyra (2008) shows as fundamental advantages of AHP/ANP, in comparison with others MCDM methods, the "user-friendly" and the application of qualitative and quantitative factors together in the evaluation.

The basic difference between them is ANP has a network structure that allows the analysis of dependence among elements of the model, which makes it more powerful in situations with uncertainty, and let the problem analyzed closer to reality. 


\subsection{AHP application in Brazilian automotive industry}

In AHP applications, the data needed are judgments to compound matrix of comparisons between elements of the model (alternatives/subcriteria or criteria) two to two. Data generated by method application include the decision matrix (compounded by performance values of alternatives/subcriteria for each criterion), the consistency ratio (CR) values of the judgments and the decision vector (compounded by global performance values of alternatives/subcriteria) (Salomon, 2004). Saaty (1994) apud Cheng \& Li (2007) suggests limit values for CR in proportion to matrices' order: 0.02 to $3 \times 3 ; 0.08$ to $4 \times 4$; and 0.1 to all others, being this last the most used in conjunction with 0.2 , proposed years later (Saaty, 2001).

According to the model shown in Figure 2, RL programs identified in automotive industry are economic (EP), image (IP) and citizenship (CP). Each of them has included a set of activities. In this case particularly, we are not interested in selecting alternatives. We intend to determine the importance of each RL program has on corporate performance, considering that indicators have same importance in each BSC perspective.

The following tables show different judgment matrices and the final result of the AHP application. Table 2 presents the judgments of relative importance of RL programs (criteria), according to perception of which affects more on corporate performance.

Table 2. Judgments and importance of the criteria.

\begin{tabular}{|l|l|l|l|l|}
\hline & EP & IP & CP & Decision Vector \\
\hline Economic (EP) & 1 & 7 & 5 & 0.73064 \\
\hline Image (IP) & & 1 & $1 / 3$ & 0.08096 \\
\hline Citizenship (CP) & & & 1 & 0.18839 \\
\hline
\end{tabular}

Tables 3, 4 and 5 present the judgments of relative importance of each activity (subcriterion), in each RL program, and also global performances. The CR values are between 0.0311 and 0.0516 . As they are lower than 0.2 , judgments can be considered as coherent one with another.

Table 3. Judgments and global performances of the economic activities.

\begin{tabular}{|l|l|l|l|l|l|}
\hline & VR & DR & RR & Decision vector & Global performance \\
\hline VR & 1 & $1 / 5$ & 3 & 0.18296 & 0.13368 \\
\hline DR & & 1 & 8 & 0.74184 & 0.54202 \\
\hline RR & & & 1 & 0.07520 & 0.05494 \\
\hline
\end{tabular}

Table 4. Judgments and global performances of the image activities.

\begin{tabular}{|l|l|l|l|l|l|}
\hline & RM & JC & DP & Decision vector & Global performance \\
\hline RM & 1 & 6 & 4 & 0.65480 & 0.05302 \\
\hline JC & & 1 & $1 / 3$ & 0.09535 & 0.00772 \\
\hline DP & & & 1 & 0.24985 & 0.02023 \\
\hline
\end{tabular}

Table 5. Judgments and global performances of the citizenship activities.

\begin{tabular}{|l|l|l|l|l|l|}
\hline & ET & CT & CD & Decision vector & Global performance \\
\hline ET & 1 & 4 & 7 & 0.70491 & 0.13280 \\
\hline CT & & 1 & 3 & 0.21093 & 0.03974 \\
\hline CD & & & 1 & 0.08416 & 0.01585 \\
\hline
\end{tabular}

The analysis of these results demonstrates that RL programs with economic purpose have great influence on corporate performance and how they are gaining increasingly relevance. In general, 
development of returnable packing (DR), value recapture of disposable packing (VR) and effluents treatment (ET), by reuse of water in productive process, are principal RL programs in automotive industry.

According to Murphy et al. (1994) apud Biraes, Prado and Gilioli (2006), the highest priorities of automobile assemblers from environmental point of view are packing and waste reduction, which is reached through using of returnable packing (that can be recycled at the lifetime end). The results of AHP application corroborated these affirmations.

However, there are other realities this method is not able to treat, such as: RL programs with economic purpose cause marginal results that may be confused with image programs (Leite, 2006); common use of RL activities as reinforcement of corporate image (Sinnecker, 2007; Neto, 2008); and automotive industry leads investments in research and development of new products and components that cut down environmental pollution (PNUMA, 2005). But here they are evaluated with little importance.

We understand this result is due to implicit consideration existent in hierarchical structures: the independence among elements of the same level. And this is assumed by AHP. The continuation presents how influence analysis among criteria and subcriteria can be included in the model by using ANP.

\subsection{ANP application in Brazilian automotive industry}

Leite (2006), in a research carried out in 44 Brazilian companies, identified RL programs in which other results, called marginal, were achieved and could be confused with real objectives.

Specifically the relation among economic, image and citizenship programs (EP, IP and CP) is shown in Figure 3.

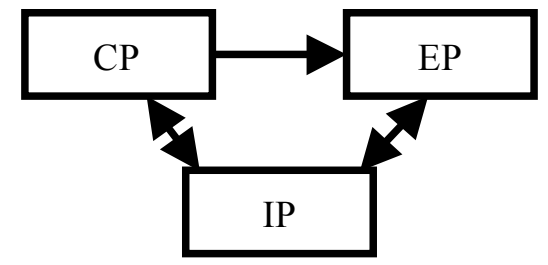

Figure 3. Network structure for RL programs in automotive industry.

Managers and specialists of automobile industry interviewed have expressed that, although they have identified RL activities within each program according to fundamental target that should be achieved, as shown in Figure 2, the final result is difficult to measure because many of these activities influence other programs. Then, it allows us to think about model shown in Figure 4, being ANP the best method to apply. In Figure 4 criteria and subcriteria were grouped and arrows in each cluster indicate influence among elements, i.e., performance of a criterion or subcriterion can influence performance of another criterion or subcriterion. 


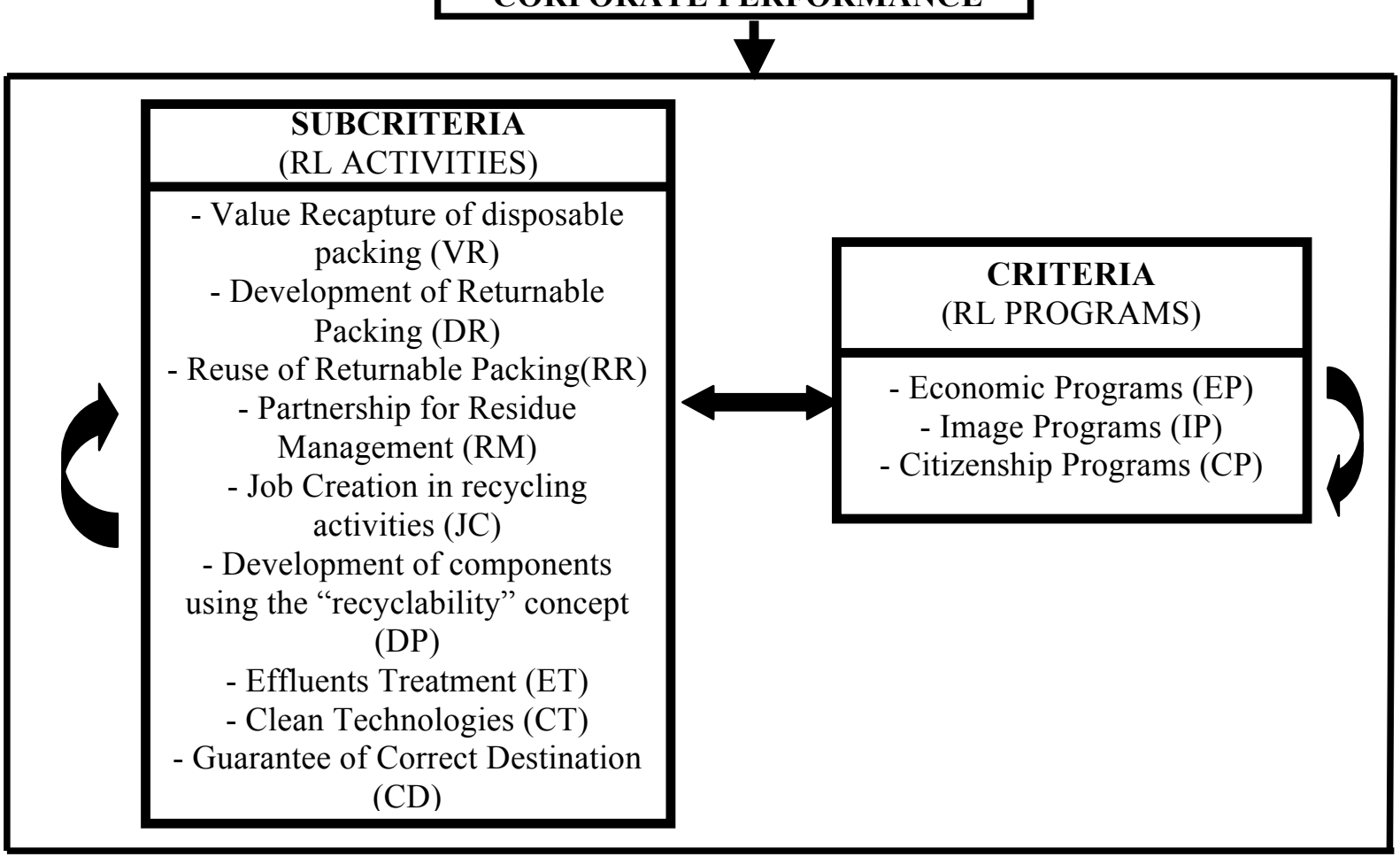

Figure 4. Network structure for RL activities in automotive industry.

The next step for ANP implementation is realization of judgments and it needs establishing dependency relations that can be represented by networks or reach ability matrices (Saaty, 1996), being these binary.

We need two matrices: the global one (for dependency between clusters) and the local one (for dependency inside clusters) (Salomon, 2004). Table 6 presents global reach ability matrix for network shown in Figure 4. As criteria and subcriteria have dependency between themselves, the components "criteria x criteria" and "subcriteria x subcriteria" are 1. Other components relate to AHP application, taking into account criteria importance (component "criteria $\mathrm{x}$ subcriteria") and subcriteria performance according to each criterion (component "subcriteria x criteria").

Table 6. Global reach ability matrix.

\begin{tabular}{|l|l|l|}
\hline Clusters & Subcriteria & Criteria \\
\hline Subcriteria & 1 & 1 \\
\hline Criteria & 1 & 1 \\
\hline
\end{tabular}

Even existing dependency relations among elements of each cluster, these one are not total. The network showed in Figure 3 presents criteria relations. The components represent the influence between reverse logistic activities (subcriteria) were obtained with questions like "Does DR performance influence DP performance?". As result of replacing criteria dependence vectors and subcriteria dependence vectors (obtained from 8 new matrices with 55 judgments), and subcriteria performance vectors and criteria importance vector (obtained from AHP) is formed the Super matrix, shown in Table 7.

Supermatrix must be weighted in order to become a column stochastic matrix. It is considered same weight for each cluster because we know that there is dependence, but not how a criterion or a subcriterion influences more than others. The powers of the Weighted Super matrix converge to a matrix also stochastic and with all columns equal. This matrix is denominated Limit Matrix (Table 8). 
Table 7. Supermatrix.

\begin{tabular}{|l|l|l|l|l|l|l|l|l|l|l|l|l|}
\hline & CD & DR & DP & JC & RM & RR & VR & ET & CT & CP & EP & IP \\
\hline CD & 0.10288 & 0.00000 & 0.05047 & 0.00000 & 0.13582 & 0.08414 & 0.05912 & 0.09141 & 0.00000 & 0.08416 & 0.00000 & 0.00000 \\
\hline DR & 0.00000 & 0.67381 & 0.43267 & 0.00000 & 0.00000 & 0.00000 & 0.00000 & 0.00000 & 0.53457 & 0.00000 & 0.74184 & 0.00000 \\
\hline DP & 0.00000 & 0.22554 & 0.38809 & 0.00000 & 0.00000 & 0.00000 & 0.00000 & 0.00000 & 0.19630 & 0.00000 & 0.00000 & 0.24985 \\
\hline JC & 0,05630 & 0.00000 & 0.00000 & 1.00000 & 0.05027 & 0.00000 & 0.00000 & 0.00000 & 0.00000 & 0.00000 & 0.00000 & 0.09535 \\
\hline RM & 0.22969 & 0.00000 & 0.00000 & 0.00000 & 0.32928 & 0.21093 & 0.12029 & 0.00000 & 0.00000 & 0.00000 & 0.00000 & 0.65480 \\
\hline RR & 0.00000 & 0.00000 & 0.00000 & 0.00000 & 0.00000 & 0.70493 & 0.25229 & 0.00000 & 0.00000 & 0.00000 & 0.07520 & 0.00000 \\
\hline VR & 0.61114 & 0.00000 & 0.00000 & 0.00000 & 0.34882 & 0.00000 & 0.56830 & 0.00000 & 0.00000 & 0.00000 & 0.18296 & 0.00000 \\
\hline ET & 0.00000 & 0.00000 & 0.00000 & 0.00000 & 0.13582 & 0.00000 & 0.00000 & 0.69094 & 0.19630 & 0.70491 & 0.00000 & 0.00000 \\
\hline CT & 0.00000 & 0.10065 & 0.12876 & 0.00000 & 0.00000 & 0.00000 & 0.00000 & 0.21765 & 0.07282 & 0.21093 & 0.00000 & 0.00000 \\
\hline CP & 0.18839 & 0.18839 & 0.18839 & 0.18839 & 0.18839 & 0.18839 & 0.18839 & 0.18839 & 0.18839 & 0.00000 & 0.00000 & 0.50000 \\
\hline EP & 0.73064 & 0.73064 & 0.73064 & 0.73064 & 0.73064 & 0.73064 & 0.73064 & 0.73064 & 0.73064 & 0.50000 & 0.00000 & 0.50000 \\
\hline IP & 0.08096 & 0.08096 & 0.08096 & 0.08096 & 0.08096 & 0.08096 & 0.08096 & 0.08096 & 0.08096 & 0.50000 & 1.0000 & 0.00000 \\
\hline
\end{tabular}

Table 8. Limit Matrix.

\begin{tabular}{|l|l|l|l|l|l|l|l|l|l|l|l|l|}
\hline & CD & DR & DP & JC & RM & RR & VR & ET & CT & CP & EP & IP \\
\hline CD & 0.01640 & 0.01640 & 0.01640 & 0.01640 & 0.01640 & 0.01640 & 0.01640 & 0.01640 & 0.01640 & 0.01640 & 0.01640 & 0.01640 \\
\hline DR & 0.16630 & 0.16630 & 0.16630 & 0.16630 & 0.16630 & 0.16630 & 0.16630 & 0.16630 & 0.16630 & 0.16630 & 0.16630 & 0.16630 \\
\hline DP & 0.05239 & 0.05239 & 0.05239 & 0.05239 & 0.05239 & 0.05239 & 0.05239 & 0.05239 & 0.05239 & 0.05239 & 0.05239 & 0.05239 \\
\hline JC & 0.02043 & 0.02043 & 0.02043 & 0.02043 & 0.02043 & 0.02043 & 0.02043 & 0.02043 & 0.02043 & 0.02043 & 0.02043 & 0.02043 \\
\hline RM & 0.07436 & 0.07436 & 0.07436 & 0.07436 & 0.07436 & 0.07436 & 0.07436 & 0.07436 & 0.07436 & 0.07436 & 0.07436 & 0.07436 \\
\hline RR & 0.02531 & 0.02531 & 0.02531 & 0.02531 & 0.02531 & 0.02531 & 0.02531 & 0.02531 & 0.02531 & 0.02531 & 0.02531 & 0.02531 \\
\hline VR & 0.05657 & 0.05657 & 0.05657 & 0.05657 & 0.05657 & 0.05657 & 0.05657 & 0.05657 & 0.05657 & 0.05657 & 0.05657 & 0.05657 \\
\hline ET & 0.05963 & 0.05963 & 0.05963 & 0.05963 & 0.05963 & 0.05963 & 0.05963 & 0.05963 & 0.05963 & 0.05963 & 0.05963 & 0.05963 \\
\hline CT & 0.02860 & 0.02860 & 0.02860 & 0.02860 & 0.02860 & 0.02860 & 0.02860 & 0.02860 & 0.02860 & 0.02860 & 0.02860 & 0.02860 \\
\hline CP & 0.08845 & 0.08845 & 0.08845 & 0.08845 & 0.08845 & 0.08845 & 0.08845 & 0.08845 & 0.08845 & 0.08845 & 0.08845 & 0.08845 \\
\hline EP & 0.24613 & 0.24613 & 0.24613 & 0.24613 & 0.24613 & 0.24613 & 0.24613 & 0.24613 & 0.24613 & 0.24613 & 0.24613 & 0.24613 \\
\hline IP & 0.16542 & 0.16542 & 0.16542 & 0.16542 & 0.16542 & 0.16542 & 0.16542 & 0.16542 & 0.16542 & 0.16542 & 0.16542 & 0.16542 \\
\hline
\end{tabular}


The normalization of the Limit Matrix results the priorities of the criteria and the subcriteria (Table 9).

Table 9. Priorities of the criteria and the subcriteria.

\begin{tabular}{|l|l|l|l|l|l|l|l|l|l|}
\hline Criteria & \multicolumn{4}{l|}{ Economic Programs (EP) } & \multicolumn{4}{l|}{ Image Programs (IP) } & \multicolumn{3}{l|}{ Citizenship Programs (CP) } \\
\hline Priorities & \multicolumn{2}{|l|}{0.49226} & \multicolumn{3}{l|}{0.33084} & \multicolumn{1}{l|}{} \\
\hline Subcriteria & VR & DR & RR & RM & JC & DP & ET & CT & CD \\
\hline Priorities & 0.1131 & 0.3326 & 0.0506 & 0.1487 & 0.0408 & 0.1047 & 0.1192 & 0.0572 & 0.0328 \\
\hline
\end{tabular}

The ANP application corroborates the fact of RL programs with economic purpose have the greatest influence on corporate performance, but it is lower than the one obtained with AHP application and this result is more real because of the marginal results, previously mentioned and shown in Figure 3.

With regard to subcriteria (RL activities), it was also ratified that development of returnable packing (DR), value recapture of disposable packing (VR) and effluents treatment (ET) are the most important, with less importance though.

The result most surprising, related to subcriteria, is the highlight given to development of components using the "recyclability" concept (DP). It reinforces ANP's result, since it is in accordance with different references that analyze this aspect as fundamental in automotive industry (Sinnecker, 2007; Neto, 2008; PNUMA, 2005).

The increase of importance to residue management (RM) can be a particular case because one of the industries analyzed belongs to a partnership for solid residue management. However, the waste reduction is among targets of automobile assemblers and a correct RM can be a way to reach it.

\section{Conclusions}

The analysis of relevant studies from several authors has shown that, although still without establishing a quantitative impact, RL policies and practices affect strongly and positively corporate performance indicators that are closely linked to the corporate sustainability concept. Therefore, it would be necessary to find methods and tools that allow evaluating this influence.

Thus, answering the main question of this research, we are able to affirm that both methods - AHP and ANP - can be used to evaluate the influence that RL practices have on corporate performance indicators, but the result obtained with the application of each of them can vary in terms of efficiency and reliability. For the specific case examined here, it was possible to establish priorities with both methods.

From efficiency standpoint, the best method is AHP, because it requires a smaller number of judgments (4 matrices with 12 judgments), so the consumption of time and resources decreases.

The inclusion of dependence analysis among elements improves the reliability of the results, which are more compatible to the reality of the Brazilian automotive sector, in accordance with results obtained from different studies, such as: Neto (2008) that shows 13 RL programs of automotive companies operating in Brazil; Leite (2006) that demonstrates the existence of marginal results in programs with various goals; and Sinnecker (2007) that evaluate image results of RL programs with economic and citizenship goals in 4 great companies operating in Brazil. So, we can say the ANP offers the best result, but it has as disadvantage the increase of time consumed (in this case, 8 new matrices with 55 judgments).

Although advantages and disadvantages of each method, both require specific knowledge and familiarity with processes of the company to identify correctly all activities and dependence relations between them. 
Future researches should analyze companies of different business sector or different type/position of the reverse channel, since these are relevant characteristics related to RL programs and corporate performance indicators.

With respect to AHP and ANP applications, we believe that the best way is the use combined of them, considering that the first one can assist in the development of a hierarchy that subsequently will be used by the second method.

\section{REFERENCES}

Alves, S.N.L., Simões, S.A.C., \& Neyra, B.M.C. (2008). Literature review about ANP method application in problem of supplier selection. Brazilian Symposium of Operational Research. September 2-5, João Pessoa, Brazil. (in Portuguese)

Amaral, S.P. (2003). Development of indicators and a model report for environmental, social and economic sustainability: a proposal for the Brazilian oil industry. (Doctoral dissertation, Federal University of Rio de Janeiro, 2003). (in Portuguese)

Biraes, A., Prado, P.B., \& Gilioli, R.R. (2006). The environmental logistics in the Brazilian automotive sector. National Production Engineering Meeting, October 12-14, Fortaleza, Brazil. (in Portuguese)

Braga Junior, S.S., Costa, P.R., \& Merlo, E.M. (2006). Reverse Logistics as an alternative of gain for the retail: a case study in a medium supermarket. Symposium of Production Administration, Logistics and International Operations, August 29-31, São Paulo, Brazil. (in Portuguese)

Campos, L.M.S. (2001). SGADA - Environmental Performance Management and Evaluation System: a proposal of implementation. (Doctoral dissertation, Federal University of Santa Catarina, 2001). (in Portuguese)

Chaves, G.L.D., \& Alcântara, R.L. (2006). Reverse Logistics as an activity generator of competitive advantage for refrigerated food supply chain. Symposium of Production Engineering, November 6-8, Bauru, Brazil. (in Portuguese)

Cheng, E. W. L., \& Li, H. (2007). Application of ANP in process models: An example of strategic partnering. Building and Environment v.42, 278-287.

Cruz, M.M., \& Ballista, B.R. (2006). Reverse Logistics of the health institutions of Grande Vitória. Symposium of Production Engineering, November 6-8, Bauru, Brazil. (in Portuguese)

Daugherty, P.J., Autry, Ch.W., \& Ellinger, A. E. (2001). Reverse Logistics: The relationship between resource commitment and program performance. Journal of Business Logistics, 22(1), 107-123.

Epelbaum, M. (2004). The influence of the environmental management on competitiveness and the organizational success. (Master's Dissertation, Polytechnic School of the University of São Paulo, 2004). (in Portuguese)

Fleischman, M., Krikke, H. R., Dekker, R., \& Flapper, S.D.P. (2000). A characterization of logistics network for product recovery. Omega, 28, 653-666.

Hammond, D., \& Beullens, P. (2007). Closed-loop supply chain network equilibrium under legislation. European Journal of Operational Research, 183, 115-129. 
Hernández, C.T., Marins, F.A.S., \& Castro, R.C. (2008). Reverse Logistics and Balanced Scorecard: a proposal of application. International Conference on Business Science, October 16-19, Santa Clara, Cuba. (in Portuguese)

Hernández, C.T., Marins, F.A.S., \& Castro, R.C. (2007). Reverse Logistics and corporate social responsibility: the influence on corporate performance indicators. Symposium of Production Engineering, November 6-8, Bauru, Brazil. (in Portuguese)

Herrero, E.F. (2005). Balanced Scorecard and strategic management: a practical approach. Rio de Janeiro: Campus. (in Portuguese)

Kaplan, R.S., \& Norton, D.P. (2000). Organization orientated to strategy. Rio de Janeiro: Campus. (in Portuguese)

Kaplan, R.S., \& Norton, D.P. (1997). The strategy in action. Rio de Janeiro: Campus. (in Portuguese)

Lakatos, E.M., \& Marconi, M.A. (1986). Scientific Methodology. São Paulo: Atlas. (in Portuguese)

Leite, P.R. (2005). Reverse Logistics: corporate categories and practices in programs implemented in Brazil - a test of categorization. Retrieved July, 2006, from http://www.meusite.mackenzie.com.br/pl (in Portuguese)

Leite, P.R. (2006). Strategic drivers in reverse logistics programs in Brazil. Symposium of Production Administration, Logistics and International Operations, August 29-31, São Paulo, Brazil. (in Portuguese)

Leite, P.R. (2000). Reverse distribution flows: factors of influence on quantities of recycled material. Symposium of Production Administration, Logistics and International Operations, August 28-30, São Paulo, Brazil. (in Portuguese)

Murphy, P., Poist, R.F, \& Braunscheweig, C.D. (1994). Management of environmental issues in logistics current status and potential. Transportation Journal, 34(1), 48-56.

Neto, J.A. (2008). Sustainability in the Brazilian automotive productive chain: a multiple case study. Retrieved August, 2008, from http://www.administradores.com.br/noticias/volkswagen

PNUMA. (2005). Retrieved July, 2005, from http://www.brasilpnuma.org.br (in Portuguese)

Ravi, V., Shankar, R., \& Tiwari, M.K. (2005). Analyzing alternatives in reverse logistics for end-oflife computers: ANP and balanced scorecard approach. Computers \& Industrial Engineering, 48, 327356.

Revlog (2004). Reverse Logistics study group. Retrieved October, 2004, from http://www.fbk.eur.nl/OZ/REVLOG/Introduction.htm (in Portuguese)

Rogers, D.S., \& Tibben-Lembke, R.S. (1998). Going Backwards: Reverse Logistics trends and practices. Reno, University of Nevada.

Rovere, E.L. (2001). Sustainability indicators for enterprises. Managerial workshop about sustainable development, Rio de Janeiro, Brazil. (in Portuguese) 
Saaty T. L. (2008). Relative Measurement and Its Generalization in Decision Making Why Pairwise Comparisons are Central in Mathematics for the Measurement of Intangible Factors The Analytic Hierarchy/Network Process. RACSAM, v.102 n.2, 251-318.

Saaty, T. L. (2001). Analytic Hierarchy Process, vol. 2 Decision Making for Leaders. Vol. II of the AHP Series Thomas L. Saaty, 315 pp., RWS Publ. (new ed.).

Saaty, T.L. (1996). Decision making with dependence and feedback: the analytic network process. Pittsburgh, PA: RWS Publications.

Saaty, T. L. (1994). How to make a decision: the analytic hierarchy process. Interfaces, v.24, n.6, 1943.

Salomon, V. (2004). Performance of decision aid modeling on Production Planning and Control analysis. (Doctoral dissertation, Polytechnic School of the University of São Paulo, 2004). (in Portuguese)

Silva, L.S.A., \& Quelhas, O.L.G. (2006). Sustainable development and consequences for equity costs in public companies. Management \& Production, 13 (3), 385-393. (in Portuguese)

Sinnecker, C. A. (2007). Study about the importance of Reverse Logistics in four large companies of the Metropolitan Area of Curitiba. (Master's Dissertation, Pontifical Catholic University of Paraná, 2007). (in Portuguese).

Souza, M.T.S., Vasconcelos, M.W., \& Pereira, R.S. (2006). The contribution of Reverse Logistics to adequacy of the Solid Residue National Policy: a case study in packing sector. Symposium of Business Management and Strategy, July 10-13, Rio de Janeiro, Brazil. (in Portuguese)

Taliscali, A.K., \& Ercan, S. (2006). The Analytic Hierarchy \& the Analytic Network Processes in multicriteria decision making: a comparative study. Journal of Aeronautics and space technologies, 2 (4), 55-65.

Tibben-Lembke, R.S. (2000). Life after death - reverse logistics and the product life cycle. International Journal of Physical Distribution \& Logistics Management, 32(3), p. 223-244.

Trigueiro, F.R. (2002). Reverse Logistics. Retrieved August, 2006, from http://www.guiadelogistica.com.br/ (in Portuguese)

Valente, T.R.G. (2002). Relationship Marketing and CRM: a customer management analysis in financial sector. Retrieved May, 2005, from http://www.ead.fea.usp.br/tcc/trabalhos/Artigo_Thais\%20Valente.pdf (in Portuguese)

Vergara, S.C. (2005). Research methods in business administration. São Paulo: Atlas. (in Portuguese)

Wu, W. W., \& Lee, Y. T. (2007). Selecting knowledge management strategies by using The Analytic Network Process. Expert Systems with Applications, v.32, 841-847. 